[Chem. Pharm. Bull.

34( 4$) 1740-1747(1986)]$

\title{
Specific Release of Rat Liver Microsomal Catalase
}

\author{
Yuji Sugita, ${ }^{*, a}$ Toworu OMata, ${ }^{a, 1)}$ TaKashi Tobe, ${ }^{a}$ \\ Terufumi SaKamoto, ${ }^{a}$ Motowo Tomita, ${ }^{a}$ \\ and TOKUHIKo HigaSHI ${ }^{b}$ \\ School of Pharmaceutical Sciences, Showa University, ${ }^{a}$ Hatanodai 1-5-8, \\ Shinagawa-ku, Tokyo 142, Japan and Institute of Basic Medical \\ Sciences, University of Tsukuba, ${ }^{b}$ Sakura-mura, \\ Niihari-gun, Ibaraki 305, Japan
}

(Received September 4, 1985)

\begin{abstract}
The recovery of catalase in the microsomal fraction of rat liver was influenced by the solution used for preparation. When microsomes were prepared with TMKS-solution $(50 \mathrm{~mm}$ Tris- $\mathrm{HCl}, \mathrm{pH}$ $7.4,5 \mathrm{mM} \mathrm{MgCl}_{2}, 25 \mathrm{mM} \mathrm{KCl}$ and $0.25 \mathrm{M}$ sucrose), the catalase content of the microsomes (TMKSmicrosomes) was about $50 \%$ of that in the microsomes (PS-microsomes) prepared with PS-solution (10 mM phosphate buffer, $\mathrm{pH}^{7} 7.0$, and $0.25 \mathrm{M}$ sucrose).

Upon washing of PS-microsomes with $0.25 \mathrm{M}$ sucrose containing $50 \mathrm{~mm}$ Tris, about $30 \%$ of catalase as well as fatty acyl-CoA oxidase, both being peroxisomal enzymes, was released. On the other hand, membrane marker enzymes, glucose-6-phosphatase and nucleoside diphosphatase, and a secretory albumin, were not substantially released by this treatment. No effect was observed on the release of catalase by washing PS-microsomes with $0.25 \mathrm{M}$ sucrose containing $\mathrm{MgCl}_{2}$ or $\mathrm{KCl}$, but Tris caused selective release of catalase.

These two types of microsomal catalase, i.e., that released by Tris (TS-released catalase) and that not released (TS-microsomal catalase), were labeled by injection of ${ }^{3} \mathrm{H}$-leucine. A peak in the specific radioactivity appeared in the former at $50 \mathrm{~min}$ and in the latter at $30 \mathrm{~min}$ after the injection, and both thereafter lost their labels rapidly. Based on these results, a possible intracellular transition of catalase, TS-microsomal catalase $\rightarrow$ TS-released catalase $\rightarrow$ peroxisomal catalase, is discussed.
\end{abstract} labeling

Keywords_-rat liver; peroxisome biogenesis; microsomal catalase; specific release; in vivo

\section{Introduction}

It is not clear how nascent catalase, synthesized on the ribosomes, is incorporated into the peroxisomes. No matter whether liver catalase is synthesized solely on free ribosomes, ${ }^{2)}$ or by both free and membrane-bound ribosomes, ${ }^{3,4)}$ it should associate in some way with membrane materials before accumulating inside the peroxisomes. When rats were injected with radioactive amino acids, microsomal and cytosol catalases in liver exhibited a peak in specific radioactivity appearing before the specific activity of peroxisomal catalase reached the plateau. ${ }^{5}$ It is conceivable that these fractions of catalase contain intermediate molecules on the pathway to the peroxisomes. ${ }^{6-8)}$ Thus, it is important to clarify the nature of microsomal catalase for elucidating the mechanism of its intracellular transport.

In this article, we report a difference in the recovery of catalase in the microsomes prepared by the use of two conventional solutions. The results indicated that Tris caused the selective release of catalase from the microsomes. The possibility that the catalase thus released may represent an intermediate stage in transfer from the ribosomes to the peroxisomes is discussed. 


\section{Materials and Methods}

Preparation of Microsomes from Rat Liver_-Subcellular fractionation was carried out as described in the previous report. $^{8)}$ Male rats weighing $100-150 \mathrm{~g}$ were used. Livers were homogenized with 4 volumes of $0.25 \mathrm{M}$

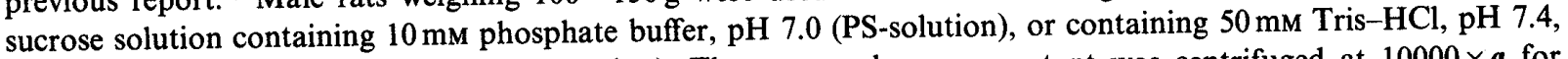
$5 \mathrm{mM} \mathrm{MgCl}$ and $25 \mathrm{mM} \mathrm{KCl}$ (TMKS-solution). The post-nuclear supernatant was centrifuged at $10000 \times g$ for $15 \mathrm{~min}$, and subsequently at $105000 \times \mathrm{g}$ for $60 \mathrm{~min}$ to obtain the peroxisomal and microsomal fractions. The final supernatant was used as the cytosol fraction. Both peroxisomes and microsomes were extracted with $1 \%$ sodium deoxycholate (DOC) and centrifuged at $150000 \times g$ for $90 \mathrm{~min}$.

Incorporation of ${ }^{3} \mathrm{H}$-Leucine into Microsomal Catalase—-Rats were given ${ }^{3} \mathrm{H}$-leucine $(150 \mu \mathrm{Ci}$ per $100 \mathrm{~g}$ body weight) by intravenous injection from the tail, and labeled for $10-90 \mathrm{~min}$. The subcellular fractionation was performed as described above. The microsomes prepared with PS-solution were washed twice with $0.25 \mathrm{M}$ sucrose containing $100 \mathrm{mM}$ Tris- $\mathrm{HCl}$ buffer, $\mathrm{pH} 7.4$ (TS-solution). The catalase released (TS-released catalase) and that remaining in the microsome pellets (TS-microsomal catalase) were immunoprecipitated, and their radioactivities were determined with a liquid scintillation counter.

Enzymatic and Immunochemical Assays - The amount of catalase was determined as described in the previous paper. ${ }^{8}$ Catalase activity was measured spectrophotometrically by following the decrease of hydrogen peroxide at $230 \mathrm{~nm}$. The amount of antigen was assayed by using the standard precipitin curve which was obtained with the purified catalase and anti-catalase antiserum specific for liver catalase.

The activity of nucleoside diphosphatase was assayed by the method of Yamazaki and Hayaishi ${ }^{\text {9) }}$ with inosine diphosphate as a substrate, and one unit of activity was defined as that producing $1 \mu \mathrm{mol}$ of P(i) per min. Glucose-6phosphatase activity was measured by the method of Segal and Washko, ${ }^{10}$ one unit of activity being the amount releasing $1 \mu \mathrm{mol}$ of $\mathrm{P}(\mathrm{i})$ per min. Reduced nicotinamide adenine dinucleotide phosphate (NADPH)-cytochrome $\mathrm{c}$ reductase activity was determined by the method of Oumura and Takesue, ${ }^{11)}$ one unit of activity being the amount reducing $1 \mu \mathrm{mol}$.of electron acceptor per min. Fatty acyl-CoA oxidase activity was assayed by the method of Osumi and Hashimoto, ${ }^{12)}$ with palmitoyl-CoA as a substrate. One unit of activity was the amount oxidizing $1 \mathrm{nmol}$ of the substrate per min.

The amount of albumin was assayed immunochemically. Antialbumin antiserum was prepared from rabbits which had been immunized with rat serum albumin (commercial product).

Electrophoresis - - Sodium dodecyl sulfate (SDS)-polyacrylamide gel electrophoresis (PAGE) was performed on $10 \%$ gel containing $0.1 \%$ SDS by the method of Laemmli. ${ }^{13)}$ The gel was stained with Coomassie brilliant blue. The various catalase preparations were also analyzed by PAGE according to the method of Davis, ${ }^{14)}$ and the gel was stained for enzyme activity by the method of Woodbury et al. ${ }^{15}$ )

Other Procedures - Soluble P(i) was measured by the method of Fiske and SubbaRow. ${ }^{16)}$ Protein was determined by the method of Lowry et $a l .^{17)}$ using bovine serum albumin as a standard.

Chemicals - L- $\left[4,5-{ }^{3} \mathrm{H}\right]$ Leucine (specific radioactivity: $133 \mathrm{Ci} / \mathrm{mmol}$ ) was purchased from the Radiochemical Centre, Amersham. Horseradish peroxidase, rat and bovine serum albumins, glucose-6-phosphate, inosine diphosphate, and SDS were purchased from Sigma Chemical Co., NADPH and cytochrome c from Boehringer Mannheim, and palmitoyl-CoA from P. L. Biochemicals.

\section{Results}

\section{Recovery of Microsomal Catalase}

Microsomes were prepared with PS- or TMKS-solution, and the amounts of catalase, protein and a few marker enzymes were determined (Table I). Activities of the marker enzymes in the microsomes prepared with PS-solution were almost equal to those given in the literature. $^{9-11)}$

When the microsomes were prepared with TMKS-solution (TMKS-microsomes), the amount of catalase was less than $50 \%$ of that in the microsomes prepared with PS-solution (PS-microsomes), while the amounts of protein and microsomal membrane proteins (nucleoside diphosphatase and NADPH cytochrome $\mathrm{c}$ reductase) were about $80 \%$.

The $20 \%$ decrease in the amount of protein and the two microsomal membrane enzymes could be explained by the decreased recovery of the TMKS-microsomes (Table II). When $\mathrm{MgCl}_{2}$ was added at the final concentration of $5 \mathrm{mM}$ to the postmitochondrial supernatant prepared with PS-solution, about $20 \%$ of the microsomes (in terms of protein) were precipitated by centrifugation at $10000 \times \boldsymbol{g}$ for $15 \mathrm{~min}$. Addition of $\mathrm{KCl}(25 \mathrm{~mm})$ had no effect 
TABLE I. Recovery of Microsomal Catalase and Some Marker Enzymes

\begin{tabular}{lcccc}
\hline \hline & & \multicolumn{2}{c}{ Microsomes prepared } \\
\cline { 3 - 4 } & & $\begin{array}{c}\text { With PS- } \\
\text { solution (A) }\end{array}$ & $\begin{array}{c}\text { With TMKS- } \\
\text { solution (B) }\end{array}$ & \\
\hline Protein & $(\mathrm{mg})$ & $10.8 \pm 0.87$ & $8.6 \pm 0.40$ & 79.6 \\
Catalase & $(\mu \mathrm{g})$ & $12.7 \pm 1.76$ & $5.5 \pm 1.31$ & 43.3 \\
$\quad$ Antigen & (unit) & $0.630 \pm 0.063$ & $0.288 \pm 0.069$ & 45.7 \\
$\quad$ Activity & (unit) & $13.9 \pm 1.08$ & $11.7 \pm 1.08$ & 84.2 \\
Nucleoside diphosphatase & (unit) & $4.87 \pm 0.12$ & $2.83 \pm 0.21$ & 58.1 \\
Glucose-6-phosphatase & & $1.72 \pm 0.13$ & 83.4 \\
NADPH cytochrome c reductase (unit) & $2.06 \pm 0.13$ & & \\
\hline
\end{tabular}

Microsomes were prepared with PS-solution ( $10 \mathrm{~mm}$ phosphate buffer, $\mathrm{pH} 7.0,0.25 \mathrm{M}$ sucrose) or TMKS solution ( $50 \mathrm{~mm}$ Tris- $\mathrm{HCl}, \mathrm{pH} 7.4,5 \mathrm{mM} \mathrm{MgCl}_{2}, 25 \mathrm{mM} \mathrm{KCl}, 0.25 \mathrm{M}$ sucrose). Enzyme activities were assayed using microsomal suspension, and catalase antigen was measured using microsomal extract. Values (per gram liver) are the means \pm S.D. of three experiments.

TABLE II. Aggregation of Microsomes by $\mathrm{MgCl}_{2}$

\begin{tabular}{lccc}
\hline \hline & $\begin{array}{c}\text { Protein } \\
\text { (mg/g liver) }\end{array}$ & $\begin{array}{c}\text { Catalase } \\
\text { (unit/g liver) }\end{array}$ & $\begin{array}{c}\text { Glucose-6-phosphatase } \\
\text { (unit/g liver) }\end{array}$ \\
\hline Total microsomes & 10.2 & 0.683 & 5.14 \\
Remaining microsomes. & 7.8 & 0.533 & 3.57 \\
Precipitated microsomes & 2.4 & 0.195 & 2.13 \\
\hline
\end{tabular}

$\mathrm{MgCl}_{2}$ was added at the final concentration of $5 \mathrm{~mm}$ to the post-mitochondrial supernatant prepared with PS-solution. After standing for $30 \mathrm{~min}$ in an ice bath, the mixture was centrifuged at $10000 \times g$ for $15 \mathrm{~min}$. The pellet was referred to as "precipitated microsomes." The supernatant was further centrifuged at $105000 \times g$ for $60 \mathrm{~min}$, yielding "remaining microsomes" as the sediment. The total microsomes were obtained by centrifugation of the post-mitochondrial supernatant at $105000 \times \mathrm{g}$ for $60 \mathrm{~min}$.

(data not shown).

Although glucose-6-phosphatase is one of the microsomal enzymes, its recovery in TMKS-microsomes decreased to $58 \%$ of that in PS-microsomes (Table I). This greater decrease probably resulted from its heterogenous distribution in microsomes, since this enzyme has been reported to exist mainly in the heavy microsomes. ${ }^{18)}$ Indeed, about $40 \%$ of this enzyme was present in the microsomes precipitated with $\mathrm{MgCl}_{2}$ (Table II).

"The more than $50 \%$ decrease of microsomal catalase prepared with TMKS-solution (Table I) was too much to be explained by the $\mathrm{MgCl}_{2}$-induced precipitation of microsomes, because the distribution of catalase in the precipitated and the remaining microsomes was $27: 73$.

\section{Release of Catalase from Microsomes}

Thus, about a half of the difference in catalase content between PS-microsomes and TMKS-microsomes probably represents the loss of microsomes into the sediment upon centrifugation at $10000 \times g$ for $15 \mathrm{~min}$. The other half should be due to the release of catalase from the microsomes during fractionation with TMKS-solution. Therefore, the PSmicrosomes were washed twice with TMKS-solution. By this treatment, $35 \%$ of the catalase activity (and also of the catalase antigen) was released, whereas no effect was observed on proteins or albumin (see also Table III).

We next studied which component in TMKS-solution was responsible for this selective release of catalase. PS-microsomes were washed twice with $0.25 \mathrm{M}$ sucrose solution containing $\mathrm{KCl}(5-200 \mathrm{mM})$, or $\mathrm{MgCl}_{2}(1-10 \mathrm{~mm})$, or Tris- $\mathrm{HCl}(5-100 \mathrm{mM})$. Microsomal catalase was not substantially released by washing with $\mathrm{KCl}$ (Fig. 1) or $\mathrm{MgCl}_{2}$ (Fig. 2). However, 


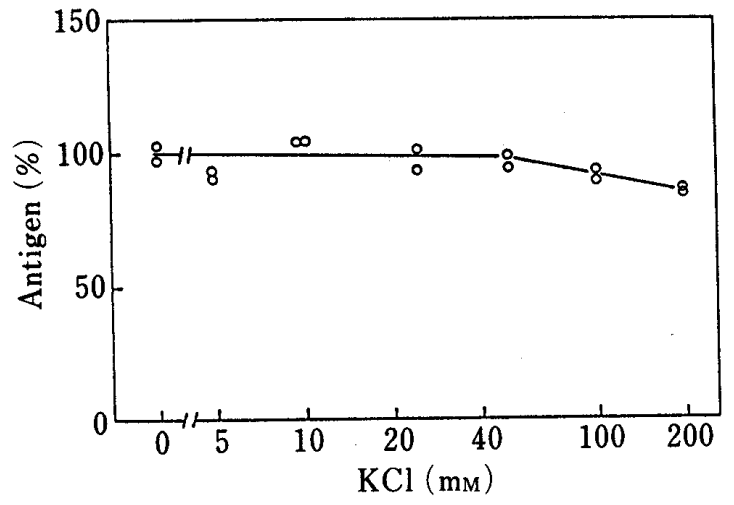

Fig. 1. Effect of $\mathrm{KCl}$ on the Release of Catalase from Microsomes

Microsomes were prepared with PS-solution, and washed twice with $0.25 \mathrm{M}$ sucrose solution containing $\mathrm{KCl}$. The amount of catalase antigen in the washed microsomes was determined after extraction with DOC and is expressed as a percentage of the control.

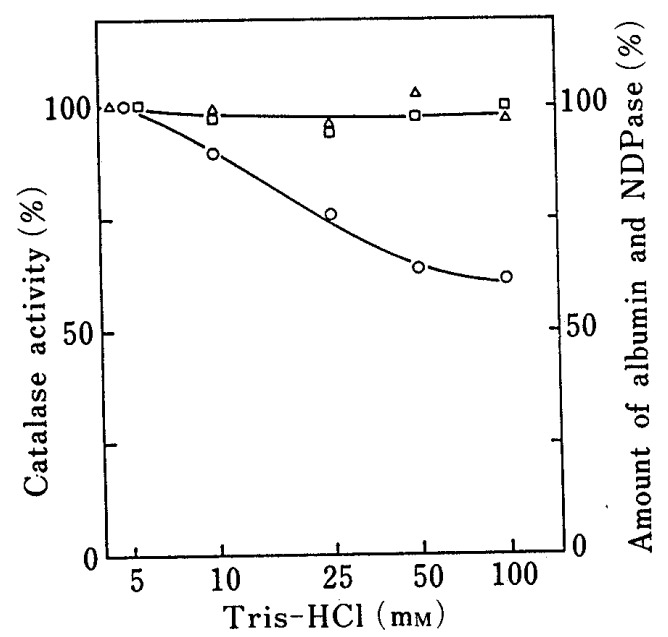

Fig. 3. Effect of Tris- $\mathrm{HCl}$ on the Release of Catalase from Microsomes

Microsomes were prepared with PS-solution, and washed twice with $0.25 \mathrm{M}$ sucrose solution containing Tris- $\mathrm{HCl}$. Activities of catalase and nucleoside diphosphatase (NDPase) and the amount of albumin in the washed microsomes were measured, and are shown as percentages of those in the microsomes washed with PS-solution. $O$, catalase; $\triangle$, NDPase; $\square$, albumin.

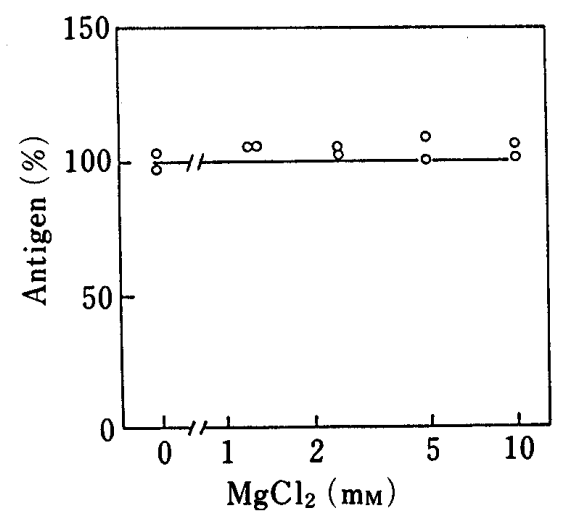

Fig. 2. Effect of $\mathrm{MgCl}_{2}$ on the Release of Catalase from Microsomes

Microsomes were prepared and washed with $\mathrm{MgCl}_{2}$ instead of $\mathrm{KCl}$, as described in the legend to Fig. 1 .

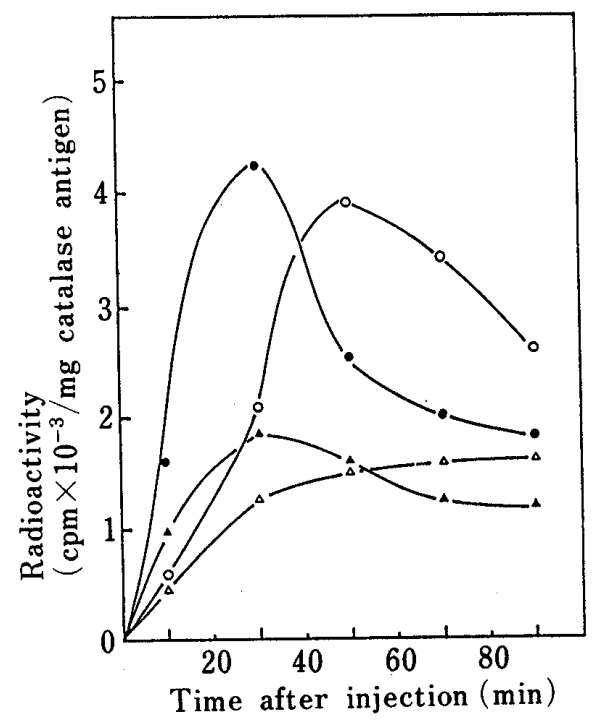

Fig. 4. ${ }^{3} \mathrm{H}$-Leucine Incorporation into Catalase of Various Liver Cell Fractions

For details see the text., TS-microsomal extracts; $\bigcirc$, TS-washings; $\triangle$, peroxisomal extracts; cytosol.

increasing concentrations of Tris- $\mathrm{HCl}$ yielded and increased release of catalase, and about $35 \%$ of the catalase activity was solubilized by addition of $50 \mathrm{~mm}$ Tris $-\mathrm{HCl}$; this value is equivalent to the amount of catalase released by washing with TMKS-solution.

Table III summarizes the results of experiments in which the microsomes prepared with PS-solution were washed with PS- or TS-solution. Proteins, albumin, glucose-6-phosphatase and nucleoside diphosphatase were not affected by washing with TS-solution, whereas $30 \%$ of the catalase as well as the fatty acyl-CoA oxidase, another peroxisomal enzyme, was rendered soluble. 
TABLE III. Release of Microsomal Catalase and Fatty Acyl-CoA Oxidase by Washing with Tris $\mathrm{HCl}$ Buffer

\begin{tabular}{lccc}
\hline \hline & PS-microsomes (A) & TS-microsomes (B) & B/A (\%) \\
\hline $\begin{array}{l}\text { Protein (mg/g liver) } \\
\text { Catalase }\end{array}$ & 13.2 & 12.6 & 95 \\
$\quad$ Activity (unit/mg protein) & 0.093 & 0.066 & 71 \\
$\quad$ Antigen ( $\mu \mathrm{g} / \mathrm{mg}$ protein) & 1.22 & 0.84 & 69 \\
$\begin{array}{c}\text { Fatty acyl-CoA oxidase } \\
\quad \text { unit/mg protein) }\end{array}$ & 4.33 & 2.92 & 69 \\
$\begin{array}{c}\text { Albumin ( } \mu \text { g/mg protein) } \\
\text { Glucose-6-phosphatase } \\
\quad \text { (unit/mg protein) }\end{array}$ & 9.25 & 9.07 & 98 \\
Nucleoside diphosphatase & 4.82 & 4.75 & 99 \\
$\quad$ (unit/mg protein) & 1.34 & 1.26 & 94 \\
\hline
\end{tabular}

Microsomes were prepared with PS-solution, washed twice with PS- or TS-solution (see the text) and precipitated by centrifugation at $105000 \times g$ for $60 \mathrm{~min}$. Each final sediment was referred to as PS-microsomes and TS-microsomes, respectively.

TABLE IV. Effect of Metal Ions on the Release of Catalase from Microsomes

\begin{tabular}{lcc}
\hline \hline & $\begin{array}{c}\text { Released catalase } \\
\text { (unit/g liver) }\end{array}$ & $\begin{array}{c}\text { Released catalase/ } \\
\text { PS-microsomal catalase } \\
(\%)\end{array}$ \\
\hline $\mathrm{TS}$ & 0.439 & 44 \\
$\mathrm{TS}+\mathrm{Zn}$ & $a)$ & 0 \\
$\mathrm{TS}+\mathrm{Hg}$ & $a)$ & 0 \\
$\mathrm{TS}+\mathrm{Mg}$ & 0.382 & 38 \\
$\mathrm{TS}+\mathrm{Mn}$ & 0.395 & 40 \\
$\mathrm{TS}+\mathrm{Ca}$ & 0.396 & 40 \\
\hline
\end{tabular}

a) Not detectable. Microsomes were prepared with PS-solution, and washed with TS-solution containing various kinds of divalent metal ions at a final concentration of $1 \mathrm{mM}$, then the catalase activities in the supernatants (released molecules) were assayed (see text).

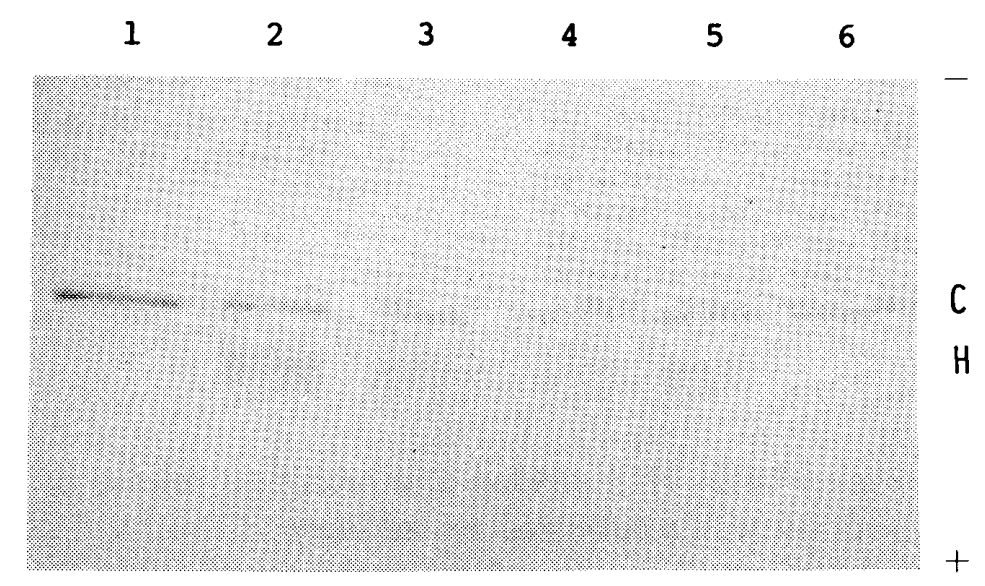

Fig. 5. SDS-PAGE of Catalase Immunocomplexes

Cytosol (lane 2), peroxisomal extracts (lane 3), TS-washings (lane 4), and TS-microsomal extracts (lane 5) were subjected to immunoprecipitation with anti-catalase antibody and each immunoprecipitate was analyzed. For comparison, a purified preparation of peroxisomal catalase was also run (lanes 1 and 6 ). The gel was stained with Coomassie brilliant blue. All samples contained $5 \mu \mathrm{g}$ of catalase. $\mathrm{C}$ and $\mathrm{H}$ in the figure mean catalase subunit and heavy chain of $\gamma$-globulin, respectively. 


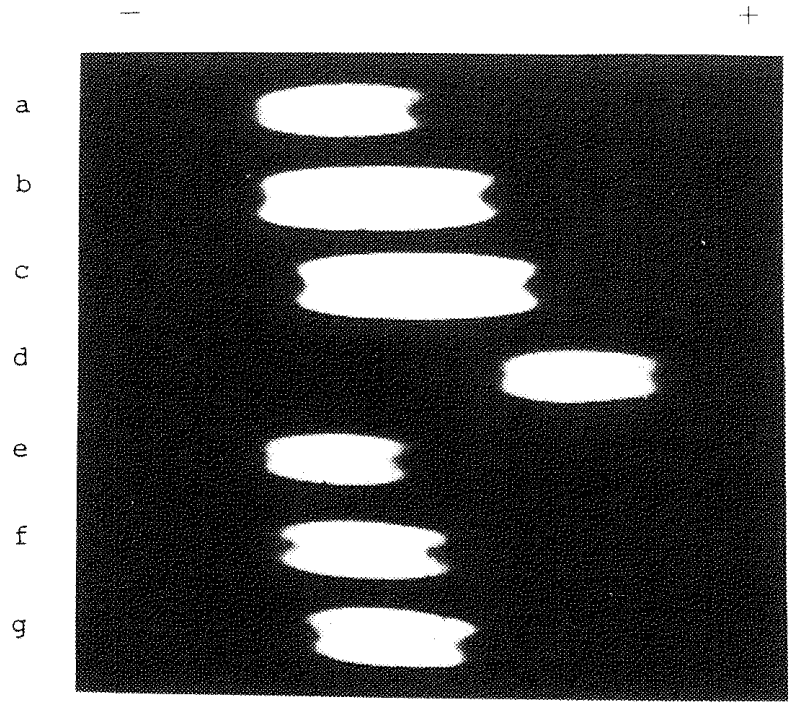

Fig. 6. Electrophoretic Analysis of Subcellular Catalase

TS-microsomal extracts (lanes a and e), TSwashings (lanes $b$ and $f$ ), cytosol (lanes $c$ and $g$ ) and peroxisomal extracts (lane d) were electrophoresed on $5 \%$ polyacrylamide gel and stained for enzymatic activity. Lanes a $-\mathrm{c}$ contained $25 \mathrm{ng}$ of catalase, and lanes $\mathrm{d}-\mathrm{g}$ contained $20 \mathrm{ng}$ each.

\section{Effect of Metal Ions on the Release of Catalase}

PS-microsomes were washed with TS-solution containing various kinds of divalent metal ions at a final concentration of $1 \mathrm{~mm}$, and the release of catalase was investigated. Among the ions studied, $\mathrm{Zn}^{2+}$ and $\mathrm{Hg}^{2+}$ suppressed the release of catalase as shown in Table IV. These metal ions did not inhibit catalase activity at all (data not shown).

\section{In Vivo Labeling of Catalase}

Figure 4 shows the kinetics of the specific radioactivities of the two types of microsomal catalase, released and not released by washing with TS-solution. The catalase in TSmicrosomes (not released by TS-washing) was more rapidly labeled than the catalase released by washing with TS-solution. The former (TS-microsomal catalase) showed a peak at $30 \mathrm{~min}$ after ${ }^{3} \mathrm{H}$-leucine injection, whereas the latter (TS-released catalase) showed one of approximately equal height at $50 \mathrm{~min}$. Thereafter, both catalases rapidly lost their radioactivities. On the other hand, the specific radioactivity of peroxisomal catalase increased gradually and reached a plateau $70 \mathrm{~min}$ after administration.

\section{SDS-PAGE of TS-Released Catalase}

TS-released catalase was immunoprecipitated and analyzed by SDS-PAGE (Fig. 5). It gave a distinct band of the size corresponding to a catalase subunit, and no other molecules were detected. Peroxisomal, cytosol, and TS-microsomal catalase also behaved identically, as shown in the figure.

\section{Electrophoretic Mobility of TS-Released Catalase}

Figure 6 shows the electrophoretic analysis of TS-released catalase in comparison with other subcellular catalases. The gel was stained for catalase enzyme activity. TS-released catalase moved slightly faster than the TS-microsomal catalase and slower than the cytosol catalase. The mobility of the peroxisomal catalase was remarkably greater than those of the other three catalases.

\section{Discussion}

The amount of catalase in microsomes prepared with TMKS-solution was less than $50 \%$ of that in microsomes prepared with PS-solution (Table I). Our results indicate that this reduction in recovery could be explained by the following two factors: (1) partial aggregation of microsomes in the presence of $\mathrm{MgCl}_{2}$ resulted in their loss into the mitochondrial fraction, 
and (2) selective release of peroxisomal enzymes, catalase and fatty acyl-CoA oxidase, from the microsomes with Tris. The aggregation of microsomes by $\mathrm{CsCl}$ or $\mathrm{MgCl}_{2}$ has been reported. ${ }^{19)}$ It was found that $30 \%$ of the catalase in PS-microsomes was released by washing with TS-solution, as shown in Table III. This release was specific for catalase, since some microsomal marker enzymes and secretory albumin were not solubilized. Furthermore it is interesting that fatty acyl-CoA oxidase, another peroxisomal enzyme, was released to the same extent as catalase.

Cytosol catalase contaminating microsomal fractions is scarcely included in the catalase released by washing with TS-solution (TS-released catalase), because the TS-released catalase showed labeling kinetics different from that of cytosol catalase (Fig. 4). In the same way, we can eliminate the peroxisomal catalase as the main candidate for the TS-released catalase. We compared the contents of some enzymes in the mitochondrial fraction prepared with PSsolution and that with TS-solution, and found that the amount of catalase was about a half in the latter fraction, whereas the recoveries of mitochondrial monoamine oxidase and of lysosomal acid phosphatase were equal in both fractions (data not shown). Our findings suggest that the catalase released by washing with TS-solution may be related to some premature stage of peroxisomes. This stage might be either buddings of endoplasmic reticulum which would mature to new peroxisomes (a classical hypothesis proposed by Novikoff and Shin ${ }^{20)}$ and de Duve and Baudhuin ${ }^{21)}$ ), or peroxisome reticulum where peroxisomal enzymes are synthesized (a hypothesis proposed by Lazarow et al. ${ }^{22)}$ ).

It has been reported that the native catalase undergoes proteolytic cleavage by a lysosomal enzyme during its isolation, ${ }^{23,24)}$ and changes in electrophoretic mobility. The two microsomal catalases described in this paper moved differently from the peroxisomal catalase in the electrophoretic field (Fig. 6), but the subunits of these three catalases appear to have the same molecular weight (Fig. 5). Robbi and Lazarow ${ }^{25}$ reported that catalase synthesized in a cell-free system had the same molecular weight as peroxisomal catalase; it is therefore unlikely that a nascent molecule possesses an additional pre-piece. Recently, they have confirmed this result by peptide mapping. ${ }^{26)}$

\section{References and Notes}

1) Present address: Japanese Red Cross Tokyo Blood Center, Sakaiminami-cho, Musashino, Tokyo 180, Japan.

2) B. M. Goldman and G. Blobel, Proc. Natl. Acad. Sci. U.S.A., 75, 5066 (1978).

3) T. Sakamoto and T. Higashi, J. Biochem. (Tokyo), 73, 1083 (1973).

4) T. Tobe and T. Higashi, J. Biochem. (Tokyo), 88, 1341 (1980).

5) T. Higashi and T. Peters, Jr., J. Biol. Chem., 238, 3952 (1963).

6) P. B. Lazarow and C. de Duve, J. Cell Biol., 59, 491 (1973).

7) P. B. Lazarow and C. de Duve, J. Cell Biol., 59, 507 (1973).

8) Y. Sugita, T. Tobe, T. Sakamoto, and T. Higashi, J. Biochem. (Tokyo), 92, 509 (1982).

9) M. Yamazaki and O. Hayaishi, J. Biol. Chem., 243, 2934 (1968).

10) H. L. Segal and M. E. Washko, J. Biol. Chem., 234, 1937 (1959).

11) T. Oumura and S. Takesue, J. Biochem. (Tokyo), 67, 249 (1970).

12) T. Osumi and T. Hashimoto, Biochem. Biophys. Res. Commun., 83, 479 (1978).

13) U. K. Laemmli, Nature (London), 227, 680 (1970).

14) B. J. Davis, Ann. N. Y. Acad. Sci., 121, 321 (1964).

15) W. Woodbury, A. K. Spencer, and M. A. Stahmann, Anal. Biochem., 44, 301 (1971).

16) C. H. Fiske and Y. SubbaRow, J. Biol. Chem., 66, 375 (1925).

17) O. H. Lowry, N. J. Rosebrough, A. L. Farr, and R. J. Randall, J. Biol. Chem., 193, 265 (1951).

18) G. Dallner, A. Bergstrand, and R. Nilsson, J. Cell Biol., 38, 257 (1968).

19) G. Dallner and R. Nilsson, J. Cell Biol., 31, 181 (1966).

20) A. B. Novikoff and W. Y. Shin, J. Microsc., 3, 187 (1964).

21) C. de Duve and P. Baudhuin, Physiol. Rev., 46, 323 (1966).

22) P. B. Lazarow, H. Shio, and M. Robbi, In 31st Mosbach Colloquim. Biological Chemistry of Organelle 
Formation, Springer-Verlag, New York, 1980, p. 187.

23) F. Mainferme and R. Wattiaux, Europ. J. Biochem., 127, 343 (1982).

24) D. Crane, R. Holmes, and C. Masters, Biochem. Biophys. Res. Commun., 104, 1567 (1982).

25) M. Robbi and P. B. Lazarow, Proc. Natl. Acad. Sci. U.S.A., 75, 4344 (1978).

26) M. Robbi and P. B. Lazarow, J. Biol. Chem., 257, 964 (1982). 